\title{
Weight-related stigma and health policy
}

\author{
Patricia Thille PhD BSc(PT), May Friedman PhD, Jenny Setchell PhD BSc(PT)
}

- Cite as: CMAJ 2017 February 13;189:E223-4. doi: 10.1503/cmaj.160975

A Ithough obesity has been shown to contribute to certain types of health problems, antifat stigma is also a threat to health. Antifat stigma adds both psychological and physiologic stress to people who are considered excessively fat, which some experts argue partially accounts for health disparities by weight. $^{1,2}$ Antifat stigma is underpinned by common assumptions that fatness is highly malleable and under individual control, implying that people who are visibly fat have poor self-control, are unknowledgeable or are not invested in their health. Puhl and Heuer's 2009 review of over 200 studies (with experimental, survey, population-based and qualitative designs) highlighted how common such stigmatizing assumptions are and the discrimination that follows in multiple sectors. ${ }^{3}$ In a 2016 systematic review and meta-analysis, Spahlholz and colleagues confirmed high rates of perceived weight-based discrimination in many life domains. ${ }^{4}$ Stigmatization can be a daily occurrence; an analysis involving 50 overweight or obese women in the United States who filled out the Stigmatizing Situations Inventory over 298 days reported more than 1000 weight-stigmatizing events. Body mass index (BMI) was the strongest predictor. ${ }^{5}$

Stigmatizing assumptions are often reinforced in medical practice and public health interventions. ${ }^{3,6}$ Canada's latest policy document on obesity, released in March 2016 by the Standing Senate Committee on Social Affairs, Science and Technology (hereinafter "Senate report"), ${ }^{7}$ reinforces antifat stigma by being entirely silent on the issue. We consider the harmful impacts of the omission of any mention of fat stigma in Canadian policy documents. We use the words fat and fatness purposefully, as stigma is about visible fatness.

The Senate report sought to create "a way forward" for policymakers and public health leaders to address obesity in Canada. Despite expert testimony (from Ian Janssen, Chair, Science Committee, Canadian Obesity Network; Timothy Caulfield, Canada Research Chair, Health Law Institute, University of Alberta; and The Hon. Mary Collins, P.C., Director of the Secretariat, BC Healthy Living Alliance) that raised fat stigma as an issue, the report excluded any recognition that stigma is part of the problem or must be considered when recommending a way forward.

A 2013 review highlighted that being stigmatized by health policies and professionals worsens health outcomes in multiple ways, including, but not limited to, reduced quality of care, psychological stress (as per the minority stress model) and through impacts on the social determinants of health. ${ }^{2}$ Changing stigmatizing policies

\section{KEY POINTS}

- Antifat stigma generates psychological and physiologic stress among people classified as overweight and obese, which may account, in part, for poor health outcomes.

- The 2016 report on obesity in Canada by the Standing Senate Committee on Social Affairs, Science and Technology ignores the issue of antifat stigma in their proposed "way forward."

- Public health interventions should involve strategies to reduce antifat stigma and avoid those that increase inequities to achieve a healthier society across all sizes.

and active antistigma campaigns have been shown to improve population health (see the 2014 review by Cook and colleagues of improvements in health indicators of stigmatized groups after policy changes [e.g., legalizing same-sex marriage] and mass media education campaigns [e.g., HIV/AIDS, mental illness]). ${ }^{8}$

Eighteen of the 21 recommendations in the Senate report focus on changing diet and physical activity behaviour of Canadians; the remaining three are about stakeholders and coordination. ${ }^{7}$ Many of these recommendations seek to influence health behaviour by working on the environment. This is a helpful shift away from the (potentially stigmatizing) focus on individual willpower as the reason for increase in body weight to a consideration of broader environmental contributors to weight (e.g., lack of incentives to exercise or access to nutritious food). However, interventions that assume fatness is reversible simply through behaviour change - regardless of how that change is made - will continue to feed stigmatizing stereotypes. If eating and exercise behaviours are the only recognized influences on weight and body composition in health policy, and if environmental changes are made but people remain visibly fat, those individuals may continue to be blamed and shamed for their bodies. In addition, if environmental changes spur more nutritious eating and an increase in physical activity but do not produce population weight loss, there is risk that the policies will be deemed failures, even though the issue is a misrecognition of determinants of weight.

Although some studies have shown behavioural interventions for patients produce modest weight reductions, a 2014 systematic review of 12 studies involving behavioural interventions to address obesity in patients in primary care settings showed that sustained, substantial weight loss from behaviour change alone is the exception rather than the rule. ${ }^{9}$ People who change eating and activity patterns 
may become weight stable or experience modest weight loss ${ }^{9}$ but usually remain categorized as overweight or obese, still appear visibly fat and thus may continue to be stigmatized. Furthermore, BMI is a low sensitivity and specificity measure of health. A study using data from the National Health and Nutrition Examination Survey (NHANES; 2005-2012) showed that some people who were classified as overweight or obese were cardiometabolically healthy, whereas many normal weight individuals had markers of cardiometabolic dysfunction. ${ }^{10}$ These findings suggest that we need to look beyond body habitus and focus more on measures of health.

Another study using NHANES data (1971-2008) found that, after controlling for changes in diet and patterns of physical activity, population weight was still higher than predicted. The authors argued that factors other than diet and physical activity - including hormonal changes (relating to stress, lack of sleep and/or exposure to environmental toxins), medication use, higher maternal ages and microbiome changes - may contribute to increases in populationlevel BMI over time. Further research is necessary to identify these factors and determine how they affect body weight. ${ }^{11}$

The Senate report only acknowledges the multifactorial and often intractable nature of weight in a limited way. In particular, the social determinants of health are mentioned but not well-developed. This is especially striking when comparing the recommendations with the list of threats to the health of Indigenous peoples noted in the body of the report. For example, recommendation no. 5 directs the government to consider how fiscal measures can help individuals with fewer socioeconomic resources (including Indigenous peoples) "choose healthy lifestyle options," despite highlighting much more pressing health policy issues affecting the lives of Indigenous communities. ${ }^{7}$ If the report's recommendations are to address causes of population weight gain, then all causes need to be considered.

We generally support the report's recommendations, for example, that nutrition labelling be more transparent, that a range of forms of exercise and joyful movement receive government support, and that food advertising targeting children be curtailed. We consider them timely. Many of these recommendations promote population health. But the way forward must also include awareness that blaming and shaming people for their size and shape does not facilitate healthy outcomes.

Weight-related health policy and practice, based on the recent Senate report or any other, should address two problems: the myopic focus on eating and physical activity (to the exclusion of action on other determinants of weight), and the absence of attention to stigmatization. Public health strategies can intensify stigmatization of people living in fat bodies. ${ }^{1}$ Indeed, some even argue stigmatization motivates individuals to change their behaviours. ${ }^{1}$ An explicit commitment to opposing stigma is needed as part of a comprehensive and workable population health strategy.

We recommend a shift in the public health and medicine narratives toward investment in a healthier society across all sizes. This shift calls for many changes. Promotion of healthy behaviours is important but should be separate from reference to body weight. Simplistic messages about weight, such as ones that imply that weight loss is always achievable or desirable, should be disrupted. Deliberate acknowledgement of fat stigma as a health issue and population health threat is necessary for this to be achieved. It would be prudent to use determinants of health and health equity analyses when evaluating proposed or existing public health strategies, to avoid pursuing strategies that will increase inequities. Studies of interventions to reduce weight should measure biological outcomes that have better specificity and sensitivity to health than BMI. These approaches can support and accommodate the diversity of bodies without stigmatization. A way forward that avoids fat shaming is likely to support overall population health better than current policy narratives.

\section{References}

1. Puhl RM, Heuer CA. Obesity stigma: important considerations for public health. Am J Public Health 2010;100:1019-28.

2. Hatzenbuehler ML, Phelan JC, Link BG. Stigma as a fundamental cause of population health inequalities. Am J Public Health 2013;103:813-21.

3. Puhl RM, Heuer CA. The stigma of obesity: a review and update. Obesity (Silver Spring) 2009;17:941-64.

4. Spahlholz J, Baer N, König HH, et al. Obesity and discrimination - a systematic review and meta-analysis of observational studies. Obes Rev 2016;17:43-55.

5. Seacat JD, Dougal SC, Roy D. A daily diary assessment of female weight stigmatization. J Health Psychol 2016;21:228-40.

6. Phelan SM, Burgess DJ, Yeazel MW, et al. Impact of weight bias and stigma on quality of care and outcomes for patients with obesity. Obes Rev 2015;16:319-26.

7. Obesity in Canada: a whole-of-society approach for a healthier Canada. Report of the Standing Senate Committee on Social Affairs, Science and Technology. Ottawa: House of Commons; 2016 Feb. 25.

8. Cook JE, Purdie-Vaughns V, Meyer IH, et al. Intervening within and across levels: a multilevel approach to stigma and public health. Soc Sci Med 2014;103:101-9.

9. Wadden TA, Butryn ML, Hong PS, et al. Behavioral treatment of obesity in patients encountered in primary care settings: a systematic review. JAMA 2014;312:1779-91.

10. Tomiyama AJ, Hunger JM, Nguyen-Cuu J, et al. Misclassification of cardiometabolic health when using body mass index categories in NHANES 2005-2012. Int J Obesity (Lond). 2016;40:883-6.

11. Brown RE, Sharma AM, Ardern $\mathrm{Cl}$, et al. Secular differences in the association between caloric intake, macronutrient intake, and physical activity with obesity. Obes Res Clin Pract 2016;10:243-55.

\section{Competing interests: None declared.}

Affiliations: The Wilson Centre (Thille), University of Toronto and University Health Network; School of Social Work (Friedman), Ryerson University; Department of Physical Therapy (Setchell), University of Toronto, Toronto, Ont.; School of Health and Rehabilitation Sciences (Setchell), The University of Queensland, Brisbane, Australia
Contributors: All of the authors made substantial contributions to the conceptualization of the article, as well as writing and revising the text. Patricia Thille was the author most responsible for final revisions of each draft. All of the authors approved the final version to be published and agreed to be accountable for all aspects of the work.
Acknowledgements: The authors thank Stephanie Nixon (University of Toronto) and Jacqui Gingras (Ryerson University) for their suggestions for the article in the early stages.

This article has been peer reviewed.

Correspondence to: May Friedman, may.friedman@ryerson.ca 